\title{
A Preliminary Study of the Effects of an Innovative Social Cognitive Theory- Driven, Yoga-Based Behavioral Intervention on Smoking Cessation
}

\author{
Manoj Sharma ${ }^{1} \&$ David E. Corbin ${ }^{2}$ \\ ${ }^{1}$ University of Cincinnati \\ ${ }^{2}$ University of Nebraska at Omaha
}

\begin{abstract}
The purpose of this study was to develop and test an innovative yoga-based behavioral intervention for smoking cessation based on social cognitive theory and compare it with an existing self-help based program. In both the groups, the antecedents of quitting based on social cognitive theory, namely, selfefficacy for quitting and self-control for quitting were tracked for six months along with self-reported daily consumption of cigarettes, self-efficacy for yoga, and past week performance of yoga behaviors. A valid and reliable 23-item instrument was utilized. The study employed an experimental design. Twenty one participants recruited in this study after informed consent and randomly assigned to the two groups. Seven $(33.3 \%)$ participants completed the study protocol and one participant who was in the yoga group was successful in quitting smoking. Statistically significant improvements occurred in the social cognitive-theory based yoga group over the self-help group for self-control for quitting $(p \leq 0.001)$ and performance of yoga behaviors $(\mathrm{p} \leq 0.05)$. This pilot study suggested that a social cognitive theory based yoga intervention was more efficacious in influencing the antecedents of smoking cessation than a selfhelp approach. This study lends support for developing and testing future interventions regarding the use of yoga as a behavioral method for smoking cessation.
\end{abstract}

(C) 2006 Californian Journal of Health Promotion. All rights reserved.

Keywords: yoga, complementary and alternative medicine, tobacco

\section{Introduction}

Smoking remains as the single most important preventable cause of death in the United States (Mumford, Levy, Gitchell, \& Blackman, 2005; Walsh \& McPhee, 2002). Currently there are over 60 million smokers in our country (McGinnis \& Foege, 1999) that account for 438,000 premature deaths and 5.5 million years of potential life lost (YPLL) annually (Centers for Disease Control \& Prevention [CDC], 2005). The total economic costs of tobacco have been estimated to be well over $\$ 100$ billion annually (Batra, Patkar, Weibel, \& Leone, 2002). Most smokers want to quit, have experimented with quitting or are planning to quit within the next one year but more than two-thirds fail in these attempts (Slovic, 2001). Several pharmacological and behavioral therapies have been tested with varying rates of success for smoking cessation (Berrettini \& Lerman, 2005; Urso, 2003).
A distinct advantage of the behavioral interventions over pharmacological interventions in facilitating smoking cessation is the lack of adverse side effects (Williams, McGregor, Borrelli, Jordan, \& Strecher, 2005). However, there is a need to enhance the efficacy of behavioral interventions and, therefore, a need to utilize innovative approaches. With growing interest in the area of complementary and alternative medical approaches in the United States (National Center for Complementary and Alternative Medicine (NCCAM, 2000), potential applications of innovative yoga-based techniques need to be explored in assisting smokers with smoking cessation. The system of yoga offers a set of such innovative techniques.

The benefits of yoga techniques have been tested as complimentary therapy to aid the healing of numerous ailments such as coronary heart disease (Manchanda \& Narang, 1998), 
hypertension (Labarthe \& Ayala, 2002; McCaffrey, Ruknui, Hatthakit, \& Kasetsomboon, 2005), depression (Brown, \& Gerbarg, 2005; Janakiramaiah et al., 2000), anxiety disorders (Kirkwood, Rampes, Tuffrey, Richardson, Pilkington, \& Ramaratnam, 2005; Miller, Fletcher, \& Kabat-Zinn, 1995), bronchial asthma (Lewith \& Watkins, 1996), and other disorders requiring extensive rehabilitation (Telles \& Naveen, 1997). Yoga techniques have been suggested for smoking cessation but have not yet been systematically tested (McIver, O'Halloran, \& McGartland, 2004; Sahay \& Sahay, 2002).

Yoga is an ancient system of physical and psychic practice that originated during the Indus Valley civilization in South Asia. The first codified record of this methodology appeared in the Yoga Sutra of Patanjali around 3rd or 4th Century BC (Singh, 1983). The system consists of eight-fold path or asthangayoga. In contemporary literature, yoga has been defined in several ways and a more acceptable modern interpretation implies the systematic application of techniques to promote harmony in the human body, mind, and environment (Maharishi, 1992). The traditional practice of yoga was quite rigorous and arduous and entailed lifelong devoted practice and adherence to strict austerities. Today many schools of yoga have simplified the techniques making them more suitable for users in different walks of life. The eight conventional steps of asthangayoga consist of yama (rules for living in society), niyama (self-restraining rules), asana (low physical impact postures), pranayama (breathing techniques), pratyahara (detachment of mind from the senses), dharana (concentration), dhyana (meditation), and samadhi (union with super consciousness). Different schools of yoga utilize all or some of the above practice steps. One well-evolved school of yoga is Kundalini Yoga or the system of primordial energy unification (Mahan, 1981, Maharishi, 1992). The hallmark of this school is that it starts from the seventh step that of meditation (dhyana) which can be of particular benefit in combating the negative effects of emotional stress and enhancing coping among smokers while they make attempts to quit smoking and remaining in cessation. In Kundalini Yoga the meditation technique involves performing a formless contemplation at the pituitary and the hypothalamus glands. Along with the meditation (dhyana), low physical impact postures (asana) geared toward muscular strain reduction and breathing techniques (pranayama) are also practiced (Maharishi, 1987).

Therefore, the purpose of the study was to develop and test an innovative yoga-based behavioral intervention for smoking cessation (experimental group) and compare the results with an existing self-help based program (control group). If a smoker can quit smoking for six months, the chances of relapse are low and the program is considered to be successful (Prochaska, Redding, \& Evers, 2002). Hence, the antecedents of quitting based on social cognitive theory (Bandura, 1986, 1997, 2004), namely, self-efficacy for quitting and self control for quitting were also tracked for six months. Also measured was self- reported daily consumption of cigarettes (normally in a day and specifically during the past 24 hours) in both the groups. Additionally, self-efficacy for yoga and past week performance of yoga behaviors were also gauged to see if the participants were indeed adhering to the yoga practices.

\section{Methodology}

This was a Stage I research study as described by the National Institutes of Health (NIH) (1999) that involves development, modification, and pilot testing of novel behavioral interventions. A purposive sample of smokers from Omaha, Nebraska was recruited after obtaining informed consent. It was planned for the sample size for six levels (two groups $\mathrm{x}$ three times) with the desired significance criterion at alpha of 0.05 , desired power at 0.80 , and an anticipated medium effect size of 0.30 , a sample of six participants per group will be recruited (Polit \& Beck, 2003). As such a total of 36 subjects with 18 in each group (experimental and control) were planned. It was envisaged that over six months a possible attrition of about $10 \%$ in the sample would occur. As a result, 40 subjects were to be recruited with random assignment of 20 subjects each into the yogabased experimental group and the self-help 
control group. However, no incentives were budgeted for enrolling the participants in the study other than providing yoga mats, and a video to the participants in the experimental arm of the study. Participants were recruited by means of an advertisement in the student newspaper of the University, a community newspaper, and flyers posted at the University.

The inclusion criteria for recruitment in the study were participants who: were (1) over the age of 18 ; (2) current smokers and who wanted to quit smoking; (3) competent and provided voluntary informed consent; (4) had intent and willingness to adhere to the assigned behavioral smoking cessation intervention - yoga-based or self-help - for a period of six months; (5) who had intent and willingness to participate in six sessions to be offered in the evenings at the University, if assigned to the yoga group; and (6) who would continue home-based practice of yoga-related procedures, if assigned to the yoga group.

People who were excluded from the study were those people who had: (1) any major disorder that limited performance of activities of daily living; (2) any overt disorder that limited the participants' ability to understand and give informed consent; (3) any history of myocardial infarction within the past six months; (4) history of any major surgery or hospitalization within the past six months; (5) any active musculoskeletal disorder that produced pain, such as uncontrolled rheumatoid arthritis.

Due to lack of provision for incentives, recruitment for the study became very difficult and only 21 participants were recruited. The smokers were randomly assigned into either the experimental yoga group $(\mathrm{n}=11)$ or the self-help control group $(\mathrm{n}=10)$.

\section{Design}

The study utilized an experimental design with data collected at: (1) start of the intervention; (2) immediately after completion of the intervention at six weeks; and (3) six months after the intervention. The primary dependent variables for comparisons between experimental and control groups were: (1) number of cigarettes smoked in the past 24 hours; (2) number of cigarettes normally smoked in a day; (3) selfefficacy for quitting with a range of 0-16 units; (4) self-control for quitting with a range of 0-16 units. In addition, in order to ascertain the adherence of smokers in the experimental group to the yoga practices, the dependent variables of self-efficacy and performing of yoga-related behaviors were also measured.

\section{Instrument}

A 31-item scale was developed and validated for face and content validity by a panel of experts in a two-round process for an earlier yoga study (Sharma, 2001). Internal consistency of this scale was also found to be acceptable with Cronbach's alpha for each of the components being over 0.80 (Sharma, 2001). Since the purpose of this study was to apply the yogabased intervention for smoking cessation, the original instrument was tailored to a 23-item scale with five subscales.

The first two items pertained to the number of cigarettes normally smoked in a day and number of cigarettes smoked in the past 24 hours.

The second subscale of four items measured self-efficacy for quitting smoking as measured by the ability to quit completely, reduce the number of cigarettes, remain smoke free for six months and remain smoke free for six months despite difficulties. The scale uses a rating of not at all sure (0), slightly sure (1), moderately sure (2), very sure (3), and completely sure (4). A summative score with a range of 0-16 units was calculated. Cronbach's alpha was found to be 0.92 and thus acceptable.

The third subscale of four items measured selfcontrol for quitting as measured by the ability to manage stress, set a goal for quitting, rewarding oneself, and exercising self control in remaining smoke free for six months. The scale used a rating of not at all sure (0), slightly sure (1), moderately sure (2), very sure (3), and completely sure (4). A summative score with a range of 0-16 units was calculated. Cronbach's alpha for this subscale was found to be 0.80 and thus acceptable. 
The fourth subscale of next four items measured self-efficacy for performing yoga-related behaviors of strain relieving low physical impact postures (asana), relaxation (shava asana), breathing techniques (pranayama) and meditation (dhyana) on the same rating scale with the summative score ranging from 0-16 units. Cronbach's alpha for this subscale was found to be 0.93 and thus acceptable.

The fifth subscale of four items measured the past week performance of the above four yogarelated behaviors on a scale of never ( 0 ), hardly ever (1), sometimes (2), almost always (3), and always (4) again with a summative score ranging from 0-16 units. Cronbach's alpha for this subscale was found to be 0.97 and thus acceptable.

The final four items measured demographic information about gender, race, education level, age, and smoking cessation efforts undertaken in the past.

\section{Intervention}

As mentioned earlier, the six-week behavioral yoga intervention has been tested and found to modify yoga-related behaviors (Sharma, 2001). The intervention consisted of yoga lessons scheduled at the convenience of the participants with the instructions for the participants to practice the techniques taught at home.

In the first lesson, the participants were given an overview of yoga and taught a set of low physical impact postures (asanas). These asanas included movements of the eyes, neck, shoulders, fine motor muscles of the hands, spinal rotations, spinal rocking with flexion, extension/ hyperextension of the spine, hip movements, knee movements, and leg postures. Not all participants assigned to the yoga group participated in the formal first lesson.

To accommodate the schedules of the participants, drop-in yoga lessons were offered at many sites with many times from which to choose. Participants had the opportunity to be introduced to breathing techniques (pranayama), and formless meditation.
The participants were given a yoga mat and a video to help them adhere to regular selfpractice at home. In addition, participants were called by research staff and encouraged to quit smoking. Having the inner potential in the form of self-efficacy for quitting and self-control to quit smoking was reinforced.

The yoga-based intervention was delivered at a University and a community setting. A video documenting all the techniques was made available to all participants in the experimental group. The control group was provided with self-help reading material in the form of the existing, "You can quit smoking consumer guide" (United States Department of Health \& Human Services, 2000). The materials in the quit smoking consumer guide included information on reasons for quitting, five keys for quitting, questions to think about, and a list of resources. Both groups were encouraged to make use of the national quit line (1-800-QUITNOW).

\section{Results}

A total of 21 participants were recruited for the study of which 11 were randomly assigned to the yoga group and 10 were randomly assigned to the control group. At six weeks, there were five participants in the yoga group and six in the control group. At six months, three participants $(27 \%)$ in the yoga group and four participants $(40 \%)$ from the control group completed the protocol of the study. The attrition rate was $48 \%$ at six weeks and $67 \%$ at six months which is very high.

Summary of the distribution of demographic variables in the two groups at baseline and at six months is depicted in Appendix A and Appendix B. No significant differences in the various categories of variables were observed between the yoga group and the control group for any of the demographic variables either at baseline or at six months.

The sample was predominantly White $(81 \%)$, majority females (71\%), and all had completed high school or more. Approximately half of the participants had tried some method of smoking cessation prior to the study, of which nicotine 
replacement therapy (NRT) was most popular (43\%) followed by Bupropion or Zyban (24\%). Other methods that were mentioned included cold turkey/own $(n=4)$, Nicorette $(n=1)$, hypnosis $(n=2)$, and counseling $(n=1)$. The age range of the participants at the baseline $(n=21)$ was between 19-57 years with a mean of 35.19 years (s.d. 11.52 years) and the mean for yoga group being 35.55 years (s.d. 3.12 years) and control group 34.80 (s.d. 4.19 years). At six months $(n=7)$ the age range of participants remaining in the study was between $21-47$ years with a mean of 34.00 years (s.d. 11.03 years) and the mean for yoga group being 33.00 years (s.d. 7.23 years ) and control group 34.75 years (s.d. 5.85 years).

Table 1 summarizes the distribution of study variables at baseline, six weeks, and six months for the yoga and the control group. Appendix C summarizes the analysis of variance (ANOVA) for the study variables. None of the between- subjects effects were found to be significant thus indicating there were no differences between the two groups.

Two interactions were found to be significant. The interaction between total self control for quitting at different time intervals and group was found to be significant $F=9.563, p=0.005$. A cell mean graph has been plotted in Appendix D. It is evident from Figure 1 that the mean total self-control in the yoga group increased significantly from base line of 6.33 units to 11.67 units at six months while it decreased in the control group from base line of 11.25 units to 8.75 units at six months. The second interaction that was found significant was between mean of yoga behaviors at different time intervals and group $(\mathrm{F}=4.192, \mathrm{p}=0.048)$. A cell mean graph is presented in Appendix E. It is evident from Appendix $\mathrm{E}$ that the mean of yoga behaviors increased at six weeks for the yoga group when compared to the control group.

Table 1

Summary of distribution of study variables at baseline, six weeks, and six months for yoga group and control group $(n=7)$

\begin{tabular}{|c|c|c|c|c|c|c|}
\hline \multirow{2}{*}{$\begin{array}{c}\text { Variable } \\
\text { (Possible range) }\end{array}$} & \multicolumn{2}{|c|}{ Baseline } & \multicolumn{2}{|c|}{ At 6 weeks } & \multicolumn{2}{|c|}{ At 6 months } \\
\hline & $\begin{array}{l}\text { Yoga group } \\
\text { Mean (s.d) }\end{array}$ & $\begin{array}{c}\text { Control } \\
\text { group } \\
\text { Mean } \\
\text { (s.d) }\end{array}$ & $\begin{array}{l}\text { Yoga group } \\
\text { Mean (s.d) }\end{array}$ & $\begin{array}{c}\text { Control } \\
\text { group } \\
\text { Mean } \\
\text { (s.d) }\end{array}$ & $\begin{array}{c}\text { Yoga } \\
\text { group } \\
\text { Mean } \\
\text { (s.d) }\end{array}$ & $\begin{array}{c}\text { Control } \\
\text { group } \\
\text { Mean (s.d) }\end{array}$ \\
\hline $\begin{array}{c}\text { Total self-efficacy for } \\
\text { quitting }(0-16)\end{array}$ & $\begin{array}{c}5.33 \\
(2.52)\end{array}$ & $\begin{array}{l}10.00 \\
(2.00)\end{array}$ & $\begin{array}{c}6.00 \\
(5.20)\end{array}$ & $\begin{array}{c}8.25 \\
(2.99)\end{array}$ & $\begin{array}{c}8.67 \\
(6.66)\end{array}$ & $\begin{array}{c}6.50 \\
(4.04)\end{array}$ \\
\hline $\begin{array}{l}\text { Total self-control for } \\
\text { quitting }(0-16)\end{array}$ & $6.33(2.52)$ & $\begin{array}{l}11.25 \\
(1.50)\end{array}$ & $\begin{array}{c}9.00 \\
(5.57)\end{array}$ & $\begin{array}{l}10.00 \\
(2.71)\end{array}$ & $\begin{array}{l}11.67 \\
(3.79)\end{array}$ & $\begin{array}{c}8.75 \\
(2.63)\end{array}$ \\
\hline $\begin{array}{l}\text { Total self-efficacy for yoga } \\
(0-16)\end{array}$ & $9.33(6.35)$ & $\begin{array}{l}12.50 \\
(1.73)\end{array}$ & $10.67(2.31)$ & $\begin{array}{c}9.75 \\
(4.27)\end{array}$ & $\begin{array}{c}8.00 \\
(6.93)\end{array}$ & $\begin{array}{c}9.75 \\
(2.06)\end{array}$ \\
\hline $\begin{array}{l}\text { Total score for yoga } \\
\text { behaviors in past week } \\
(0-16)\end{array}$ & $1.33(2.31)$ & $\begin{array}{l}2.75 \\
(2.22)\end{array}$ & $4.33(3.79)$ & $\begin{array}{c}1.50 \\
(1.91)\end{array}$ & $\begin{array}{c}2.67 \\
(2.31)\end{array}$ & $\begin{array}{c}3.00 \\
(2.00)\end{array}$ \\
\hline $\begin{array}{l}\text { Number of cigarettes } \\
\text { smoked normally in a } \\
\text { day }\end{array}$ & $\begin{array}{l}14.33 \\
(6.03)\end{array}$ & $\begin{array}{l}9.50 \\
(2.52)\end{array}$ & $\begin{array}{l}7.00 \\
(2.65)\end{array}$ & $\begin{array}{c}7.75 \\
(3.86)\end{array}$ & $\begin{array}{c}6.00 \\
(7.94)\end{array}$ & $\begin{array}{l}10.50 \\
(3.32)\end{array}$ \\
\hline $\begin{array}{l}\text { Number of cigarettes in the } \\
\text { past } 24 \text { hours }\end{array}$ & $\begin{array}{l}11.00 \\
(3.61)\end{array}$ & $\begin{array}{c}8.00 \\
(3.60)\end{array}$ & $\begin{array}{c}8.67 \\
(2.89)\end{array}$ & $\begin{array}{c}5.00 \\
(3.46)\end{array}$ & $\begin{array}{c}4.67 \\
(5.03)\end{array}$ & $\begin{array}{c}9.00 \\
(1.15)\end{array}$ \\
\hline
\end{tabular}




\section{Discussion}

The purpose of this study was to develop and test an innovative yoga-based behavioral intervention for smoking cessation and compare it with an existing self-help based program over a period of six months. From the 21 participants who started in this study, seven $(33.3 \%)$ completed the protocol and one participant who was in the yoga group was successful in quitting smoking. The attrition rate in this study is very high $(66.7 \%)$ partly due to the reason that no monetary incentives were provided to the participants when others smoking cessation studies in the same geographical areas were offering substantial monetary incentives.

Statistically significant improvements occurred in the social cognitive-theory based yoga group over the self-help group for self-control for quitting $(\mathrm{p} \leq 0.001)$ and performance of yoga behaviors $(p \leq 0.05)$. Such significant improvements were not observed for self-efficacy for quitting, self-efficacy for yoga, or the mean number of cigarettes smoked normally and during the past 24 hours. However, none of the participants in the self-help group were able to quit, but one of the three who completed the study $(33.3 \%)$ in the yoga group was able to completely quit.

Yoga is known to increase self-control (Maharishi, 1992). In this study, self-control specific to quitting was found to have increased, lending support toward the efficacy of using yoga as a behavioral intervention. Performance of yoga behaviors increased significantly at six weeks which was expected. The study needs to be replicated with better compliance from the participants through the use of monetary incentives and perhaps longer follow-up.

\section{Limitations}

The major limitations in this study are related to the research methods used to investigate using yoga as a possible complementary therapy for smoking cessation. The results of this study are not generalizable to any population other than the few smokers who were motivated to quit smoking and practice yoga.
First, the sample size was too small. A much larger sample size should have been considered at the start of the study knowing that the longterm commitments required of the research participants, without monetary compensation, may lead to a high attrition rate.

Second, the attrition rate was very high (67\%), occurring almost equally in both the groups. The attrition rate adversely affected the original sample size further, and reduced power of the statistical tests conducted. The predicted $10 \%$ attrition rate was unrealistic. The inclusion criteria may need to be revised so that research participants can be screened more carefully to avoid such attrition. Also, monetary or other forms of compensation must be made available to the research participants in future studies.

Third, the recruitment of research participants and the flexibility yoga training scheduling possibly contributed variability in the protocol used in both groups. The recruitment process, for example, was carried out over a longer period of time than initially planned, and as a result, yoga training was conducted in waves. It would have been better to recruit all research participants at the same time, and begin the study at one point in time rather than spread out over months. Also, a convenience sample was used in this study rather than a randomly selected sample of smokers. The convenience sample, however, was the sensible solution at the time to study the yoga efficacy question.

Also, efforts were made to make the yoga classes available at more convenient times and locations. This flexible scheduling made it easier for participants to take the yoga classes, thus, decreasing the likelihood attrition, but such flexible scheduling decreased the uniformity of the instruction.

Fourth, the person-to-person yoga intervention protocol was to be conducted over a six-week period, but not all participants completed the person-to-person lessons. Participants were encouraged to continue their yoga practice with the videotape or on their own for the duration of the study. Better follow up methods should have been built in to the original study design to 
assure each research participant adhered to the protocol.

Fifth, only a paper-and-pencil, self-report survey was used to measure the differences between the experimental and control groups. Other data collection methods could have been used, such as measurement of serum cotinine levels, to validate the findings in the survey.

Finally, long term assessment beyond six months was not done and it would have been nice to follow-up the participants for at least one year.

\section{Implications for Practice}

The findings of this study provide evidence that scores on measures of social cognitive theory for quitting and yoga are modifiable among smokers in a short duration person-to-person yoga intervention. The yoga intervention was short, thus making it quite practical for use by health education practitioners who work with smokers and have limited time. The techniques taught in this yoga intervention are very simple, easy to master, and can be easily taught by health educators in training others. More thought is required in ensuring compliance and decreasing attrition from such interventions. Perhaps the stages of change model (Prochaska, Redding, \& Evers, 2002) can be utilized in motivating more smokers to contemplate quitting using yoga. Modifying the constructs of decisional balance (emphasizing pros and reducing cons), consciousness raising (finding and learning new ideas), self re-evaluation (realization that behavior change is important), and environmental re-evaluation (realization of negative impacts of unhealthy behaviors on one's proximal social and physical environment) would be of primary importance (Prochaska, Redding, \& Evers, 2002).

Besides smoking cessation, yoga interventions can be utilized and tested for enhancing health promotion goals (such as stress reduction, improving problem solving, improving body flexibility etc.) and influencing specific disease treatment outcomes (such as depression, anxiety, recovery from coronary heart disease, recovery from traumatic brain injury etc) (Sharma, 2001). The yoga intervention developed and tested in this study can serve as a template for replication.

\section{References}

Bandura, A. (2004). Health promotion by social cognitive means. Health Education \& Behavior, 31, 143164.

Bandura, A. (1997). Self-efficacy. The exercise of control. New York: W. H. Freeman and Company.

Bandura, A. (1986). Social foundations of thought and action. Englewood Cliffs, NJ: Prentice Hall.

Batra, V., Patkar, A. A, Weibel, S., Leone, F. T. (2002). Tobacco smoking as a chronic disease: Notes on prevention and treatment. Primary Care, 29, 629-648.

Berrettini, W. H., \& Lerman, C. E. (2005). Pharmacotherapy and pharmacogenetics of nicotine dependence. American Journal of Psychiatry, 162, 1441-1451.

Brown, R. P., \& Gerbarg, P. L. (2005). Sudarshan kriya yogic breathing in the treatment of stress, anxiety, and depression: Part II - clinical applications and guidelines. Journal of Alternative and Complementary Medicine, 11, 711-717.

Centers for Disease Control and Prevention (CDC). (2005). Annual smoking-attributable mortality, years of potential life lost, and productivity losses: United States, 1997-2001. Morbidity and Mortality Weekly Report, 54, 625-628.

Janakiramaiah, N., Gangadhar, B. N., Naga, V. M. P. J., Harish, M. G., Subbakrishna, D. K., Vedamurthachar, A. (2000). Antidepressant efficacy of Sudarshan kriya yoga (SKY) in melancholia: A randomized comparison with electroconvulsive therapy (ECT) and imipramine. Journal of Affective Disorders, 57, 255-259.

Kirkwood, G., Rampes, H., Tuffrey, V., Richardson, J., Pilkington, K., \& Ramaratnam, S. (2005). Yoga for anxiety: A systematic review of the research evidence. British Journal of Sports Medicine, 39, 884-891. 
Labarthe, D., \& Ayala, C. (2002). Nondrug interventions in hypertension prevention and control. Cardiology Clinics, 20, 249-263.

Lewith, G. T., \& Watkins, A. D. (1996). Unconventional therapies in asthma: An overview. Allergy, 51, 761-769.

Mahan, G. P. (1981). Kundalini yoga. Erode, India: Universal Peace Sanctuary.

Maharishi, Y. V. (1992). Journey of consciousness. New Delhi, India: Macmillan India Limited.

Maharishi, Y. V. (1987). Simplified physical exercises. Erode, India: Vethathiri Publications.

Manchanda, S. C., \& Narang, R. (1998). Yoga and coronary artery disease. Indian Heart Journal, 50, 227228.

McCaffrey, R., Ruknui, P., Hatthakit, U., \& Kasetsomboon, P. (2005). The effects of yoga on hypertensive persons in Thailand. Holistic Nursing Practice, 19, 173-180.

McGinnis, J. M., \& Foege W. H. (1999). Mortality and morbidity attributable to use of addictive substances in the United States. Proceedings of the Association of American Physicians, 111, 109-118.

McIver, S., O'Halloran, P., \& McGartland, M. (2004). The impact of hatha yoga on smoking behavior. Alternative Therapies in Health \& Medicine, 10(2), 22-23.

Miller, J. J., Fletcher, K., \& Kabat-Zinn, J. (1995). Three-year follow-up and clinical implications of a mindfulness meditation-based stress reduction intervention in the treatment of anxiety disorders. General Hospital Psychiatry, 17, 192-200.

Mumford, E. A., Levy, D. T., Gitchell, J. G., \& Blackman, K. O. (2005). Tobacco control policies and the concurrent use of smokeless tobacco and cigarettes among men, 1992-2002. Nicotine and Tobacco Research, 7, 891-900.

National Center for Complementary and Alternative Medicine. (2000). Expanding horizons of health care. Five year strategic plan 2001-2005. Gaithersburg, MD: NCAAM Clearinghouse.

National Institutes of Health (NIH). (1999). Behavioral therapies development program. Retrieved November 30, 2005, from http://grants.nih.gov/grants/guide/pa-files/PA-99-107.html

Polit, D. F., \& Beck, C. T. (2003). Nursing research. Principles and methods. (7th. ed.). Philadelphia, PA: Lippincott Williams \& Wilkins.

Prochaska, J. O., Redding, C. A., \& Evers, K. E. (2002). The transtheoretical model and stages of change. In K. Glanz, B. K. Rimer, \& F. M. Lewis (Eds.), Health behavior and health education. Theory, research and practice (3rd ed.), pp. 99-120. San Francisco: Jossey Bass, Inc.

Sahay, B. K, \& Sahay, R. K. (2002). Lifestyle modification in management of diabetes mellitus. Journal of Indian Medical Association, 100, 178-180.

Singh, K. (1983). Religions of India, pp. 76-78. New Delhi: Clarion Books.

Sharma, M. (2001). Pilot test of a kundalini yoga intervention developing mind-body connection. International Journal of Yoga Therapy, 11, 85-91.

Slovic, P. (2001). Smoking: Risk, perception, and policy. Thousand Oaks, Sage Publications.

Telles, S., \& Naveen, K. V. (1997). Yoga for rehabilitation: An overview. Indian Journal of Medical Sciences, 51, 123-127.

United States Department of Health and Human Services. (2000). You can quit smoking. Consumer guide. Silver Spring, MD: U. S. Public Health Service. Retrieved December 2, 2005, from http://www.surgeongeneral.gov/tobacco/consquits.htm

Urso, P. (2003). Match the best smoking cessation intervention to your patient. Nurse Practitioner, 28, 12 21.

Walsh, J. M, \& McPhee, S. J. (2002). Prevention in the year 2002: Some news, some issues. Primary Care, 29, 727-749.

Williams, G. C., McGregor, H., Borrelli, B., Jordan, P. J., \& Strecher, V. J. (2005). Measuring tobacco dependence treatment outcomes: a perspective from the behavior change consortium. Annals of Behavioral Medicine, 29(Suppl.), 11-19. 


\author{
$\underline{\text { Author Information }}$ \\ Manoj Sharma, MBBS, CHES, Ph.D.* \\ Associate Professor, Health Promotion \& Education \\ University of Cincinnati \\ 526 Teachers College \\ PO Box 210002 \\ Cincinnati, OH 45221-0002 \\ Ph.: 513-556-3878 \\ Fax.: 513-556-3898 \\ E-Mail: manoj.sharma@uc.edu \\ David E. Corbin, Ph.D., FASHA \\ Professor, Health Education, Public Health, Women's \\ Studies, Gerontology \\ School of Health, Physical Education, \& Recreation \\ University of Nebraska at Omaha \\ Omaha, NE 68182-0216 \\ Ph.: 402-554-3237 \\ Fax.: 402-554-3693 \\ E-Mail: dcorbin@mail.unomaha.edu \\ * corresponding author
}




\section{Appendix A}

Distribution of demographic variables by group at baseline $(n=21)$

\begin{tabular}{|c|c|c|c|c|c|c|}
\hline Variable & Categories & $\begin{array}{c}\text { Yoga } \\
\text { Group } \\
(n=11) \\
(\%)\end{array}$ & $\begin{array}{c}\text { Control } \\
\text { Group } \\
(\mathbf{n}=10) \\
(\%)\end{array}$ & $\begin{array}{c}\mathbf{n} \\
(\%)\end{array}$ & $\chi^{2}$ & $\mathbf{p}$ \\
\hline \multirow[t]{2}{*}{ Gender } & Male & $2(18.2)$ & $4(40.0)$ & $6(28.6)$ & 1.222 & 0.269 \\
\hline & Female & $9(81.8)$ & $6(60.0)$ & $15(71.4)$ & & \\
\hline \multirow[t]{3}{*}{ Race } & White/Caucasian American & $9(81.8)$ & $8(80.0)$ & $17(80.9)$ & 1.348 & 0.510 \\
\hline & African American & $0(0.0)$ & $1(10.0)$ & $1(4.8)$ & & \\
\hline & Other & $2(18.2)$ & $1(10.0)$ & $3(14.3)$ & & \\
\hline \multirow[t]{3}{*}{ Education } & Less than high school & $0(0.0)$ & $0(0.0)$ & $0(0.0)$ & 0.531 & 0.466 \\
\hline & Completed high school & $6(54.5)$ & $7(70.0)$ & $13(62.0)$ & & \\
\hline & $\begin{array}{l}\text { Completed college } \\
\text { education or more }\end{array}$ & $5(45.5)$ & $3(30.0)$ & $8(38.0)$ & & \\
\hline \multirow{2}{*}{$\begin{array}{l}\text { Any smoking cessation } \\
\text { effort }\end{array}$} & No & $5(45.5)$ & $5(50.0)$ & $10(47.6)$ & 0.043 & 0.835 \\
\hline & Yes & $6(54.5)$ & $5(50.0)$ & $11(52.4)$ & & \\
\hline \multirow[t]{2}{*}{ NRT } & No & $5(45.5)$ & $7(70.0)$ & $12(57.1)$ & 1.289 & 0.256 \\
\hline & Yes & $6(54.5)$ & $3(30.0)$ & $9(42.9)$ & & \\
\hline Stress management class & No & $11(100.0)$ & $10(100.0)$ & $21(100.0)$ & & \\
\hline \multirow[t]{2}{*}{ Bupropion or Zyban } & No & $8(72.7)$ & $8(80.0)$ & $16(76.2)$ & 0.153 & 0.696 \\
\hline & Yes & $3(27.3)$ & $2(20.0)$ & $5(23.8)$ & & \\
\hline \multirow[t]{2}{*}{ Smoking cessation class } & No & $10(90.9)$ & $10(100.0)$ & $20(95.2)$ & 0.955 & 0.329 \\
\hline & Yes & $1(9.1)$ & $0(0.0)$ & $1(4.8)$ & & \\
\hline Fresh Start & No & $11(100.0)$ & $10(100.0)$ & $21(100.0)$ & & \\
\hline \multirow[t]{2}{*}{ Yoga } & No & $10(90.9)$ & $10(100.0)$ & $20(95.2)$ & 0.955 & 0.329 \\
\hline & Yes & $1(9.1)$ & $0(0.0)$ & $1(4.8)$ & & \\
\hline
\end{tabular}




\section{Appendix B}

Distribution of demographic variables by group at 6 months $(\mathrm{n}=7)$

\begin{tabular}{|c|c|c|c|c|c|c|}
\hline Variable & Categories & $\begin{array}{c}\text { Yoga } \\
\text { Group } \\
(\mathbf{n}=11) \\
(\%)\end{array}$ & $\begin{array}{c}\text { Control } \\
\text { Group } \\
(n=10) \\
(\%)\end{array}$ & $\begin{array}{c}\mathbf{n} \\
(\%)\end{array}$ & $\chi^{2}$ & $\mathbf{p}$ \\
\hline \multirow[t]{2}{*}{ Gender } & Male & $1(33.3)$ & $1(25.0)$ & $2(28.6)$ & 0.058 & 0.809 \\
\hline & Female & $2(66.7)$ & $3(75.0)$ & $5(71.4)$ & & \\
\hline Race & White/Caucasian American & $3(100.0)$ & $4(100.0)$ & $7(100.0)$ & & \\
\hline \multirow[t]{3}{*}{ Education } & Less than high school & $0(0.0)$ & $0(0.0)$ & $0(0.0)$ & 0.194 & 0.659 \\
\hline & Completed high school & $2(66.7)$ & $2(50.0)$ & $4(57.0)$ & & \\
\hline & $\begin{array}{l}\text { Completed college } \\
\text { education or more }\end{array}$ & $1(33.3)$ & $2(50.0)$ & $3(43.0)$ & & \\
\hline \multirow{2}{*}{$\begin{array}{l}\text { Any smoking cessation } \\
\text { effort }\end{array}$} & No & $2(66.7)$ & $2(50.0)$ & $4(57.0)$ & 0.194 & 0.659 \\
\hline & Yes & $1(33.3)$ & $2(50.0)$ & $3(43.0)$ & & \\
\hline \multirow[t]{2}{*}{ NRT } & No & $2(66.7)$ & $3(75.0)$ & $5(71.4)$ & 0.058 & 0.809 \\
\hline & Yes & $1(33.3)$ & $1(25.0)$ & $2(28.6)$ & & \\
\hline Stress management class & No & $3(100.0)$ & $4(100.0)$ & $7(100.0)$ & & \\
\hline \multirow[t]{2}{*}{ Bupropion or Zyban } & No & $2(66.7)$ & $3(75.0)$ & $5(71.4)$ & 0.058 & 0.809 \\
\hline & Yes & $1(33.3)$ & $1(25.0)$ & $2(28.6)$ & & \\
\hline Smoking cessation class & No & $3(100.0)$ & $4(100.0)$ & $7(100.0)$ & & \\
\hline Fresh Start & No & $3(100.0)$ & $4(100.0)$ & $7(100.0)$ & & \\
\hline Yoga & No & $3(100.0)$ & $4(100.0)$ & $7(100.0)$ & & \\
\hline
\end{tabular}




\section{Appendix C}

Summary of the analysis of variance for the study variables $(\mathrm{n}=7)$

\begin{tabular}{|c|c|c|c|c|c|}
\hline Source & Type III SS & df & MS & $\mathbf{F}$ & $\mathbf{p}$ \\
\hline \multicolumn{6}{|c|}{ Self-efficacy for quitting (SEQ): Between subjects } \\
\hline Group & 12.893 & 1 & 12.893 & 0.388 & 0.561 \\
\hline \multicolumn{6}{|l|}{ Within subjects } \\
\hline Self-efficacy for quitting (SEQ) & 1.167 & 2 & .583 & 0.076 & 0.927 \\
\hline SEQ * Group & 41.167 & 2 & 20.583 & 2.679 & 0.117 \\
\hline \multicolumn{6}{|c|}{ Self-control for quitting (SCQ): Between subjects } \\
\hline Group & 5.143 & 1 & 5.143 & 0.205 & 0.670 \\
\hline \multicolumn{6}{|l|}{ Within subjects } \\
\hline Self-control for quitting (SCQ) & 6.881 & 2 & 3.440 & 1.251 & 0.327 \\
\hline SCQ * Group & 52.595 & 2 & 26.298 & 9.563 & $0.005^{* * *}$ \\
\hline \multicolumn{6}{|c|}{ Self-efficacy for yoga (SEY): Between subjects } \\
\hline Group & 9.143 & 1 & 9.143 & 0.576 & 0.482 \\
\hline \multicolumn{6}{|l|}{ Within subjects } \\
\hline Self-efficacy for yoga (SEY) & 14.738 & 2 & 7.369 & 0.399 & 0.681 \\
\hline SEY * Group & 14.738 & 2 & 7.369 & 0.399 & 0.681 \\
\hline \multicolumn{6}{|l|}{ Yoga Behaviors (YB): Between subjects } \\
\hline Group & 0.671 & 1 & 0.671 & 0.049 & 0.833 \\
\hline \multicolumn{6}{|l|}{ Within subjects } \\
\hline Yoga behaviors (YB) & 3.198 & 2 & 1.599 & 0.802 & 0.475 \\
\hline YB * Group & 16.722 & 2 & 8.361 & 4.192 & $0.048^{*}$ \\
\hline \multicolumn{6}{|c|}{ Typical\# of cigarettes (TNC): Between subjects } \\
\hline Group & 0.099 & 1 & 0.099 & 0.004 & 0.955 \\
\hline \multicolumn{6}{|l|}{ Within subjects } \\
\hline Typical \# of cigarettes (TNC) & 79.627 & 2 & 39.813 & 2.347 & 0.146 \\
\hline TNC * Group & 75.627 & 2 & 37.813 & 2.229 & 0.158 \\
\hline \multicolumn{6}{|c|}{ Past 24 hour cigarettes (PTC): Between subjects } \\
\hline Group & 3.111 & 1 & 3.111 & 0.213 & 0.664 \\
\hline \multicolumn{6}{|l|}{ Within subjects } \\
\hline Past 24 hour cigarettes (PTC) & 32.508 & 2 & 16.254 & 1.651 & 0.240 \\
\hline PTC * Group & 67.556 & 2 & 33.778 & 3.431 & 0.073 \\
\hline
\end{tabular}




\section{Appendix D}

Cell mean graph for total self control for quitting in yoga and control groups at three time intervals

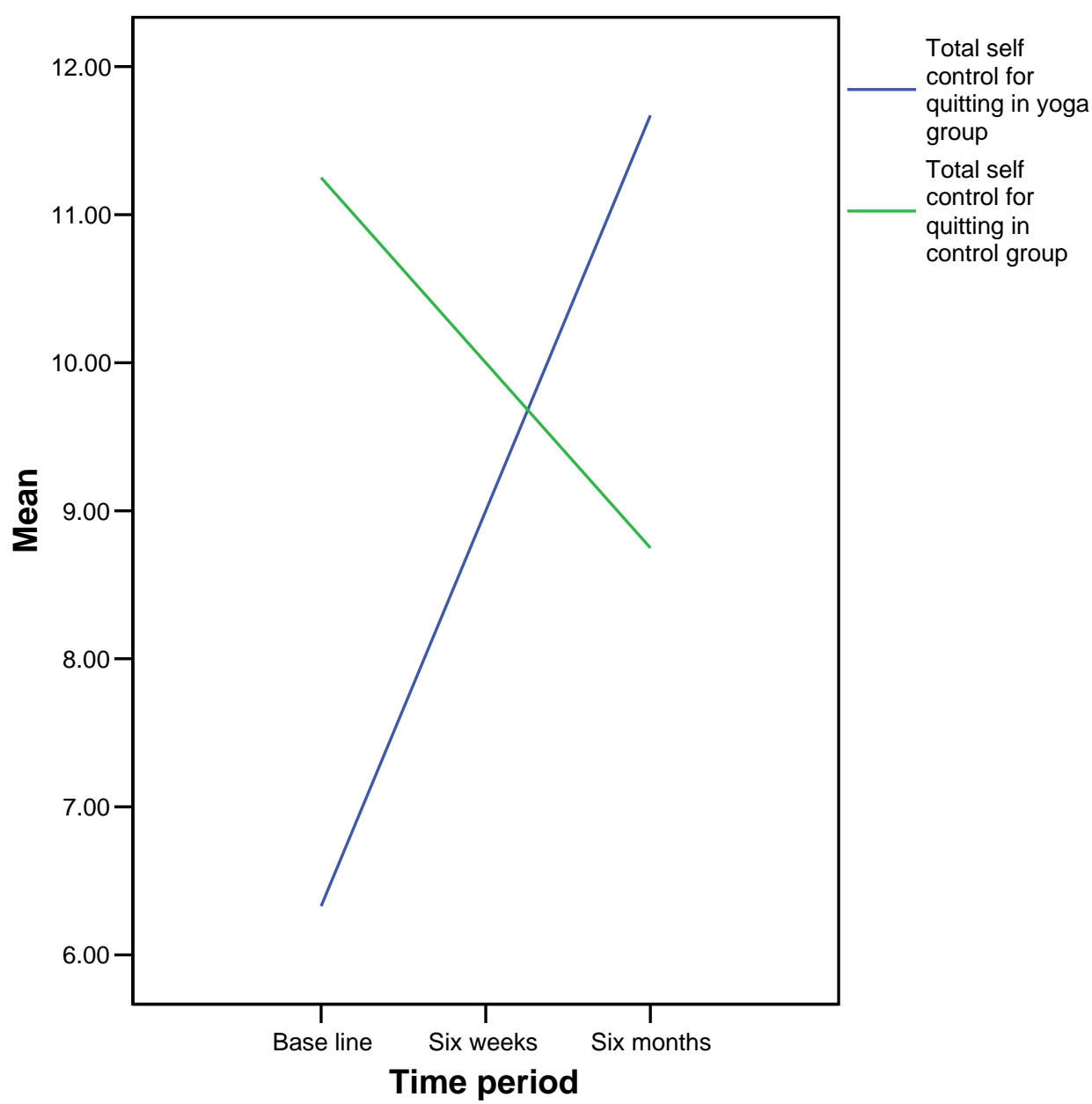




\section{Appendix E}

Cell mean graph for yoga behaviors in yoga and control groups at three time intervals

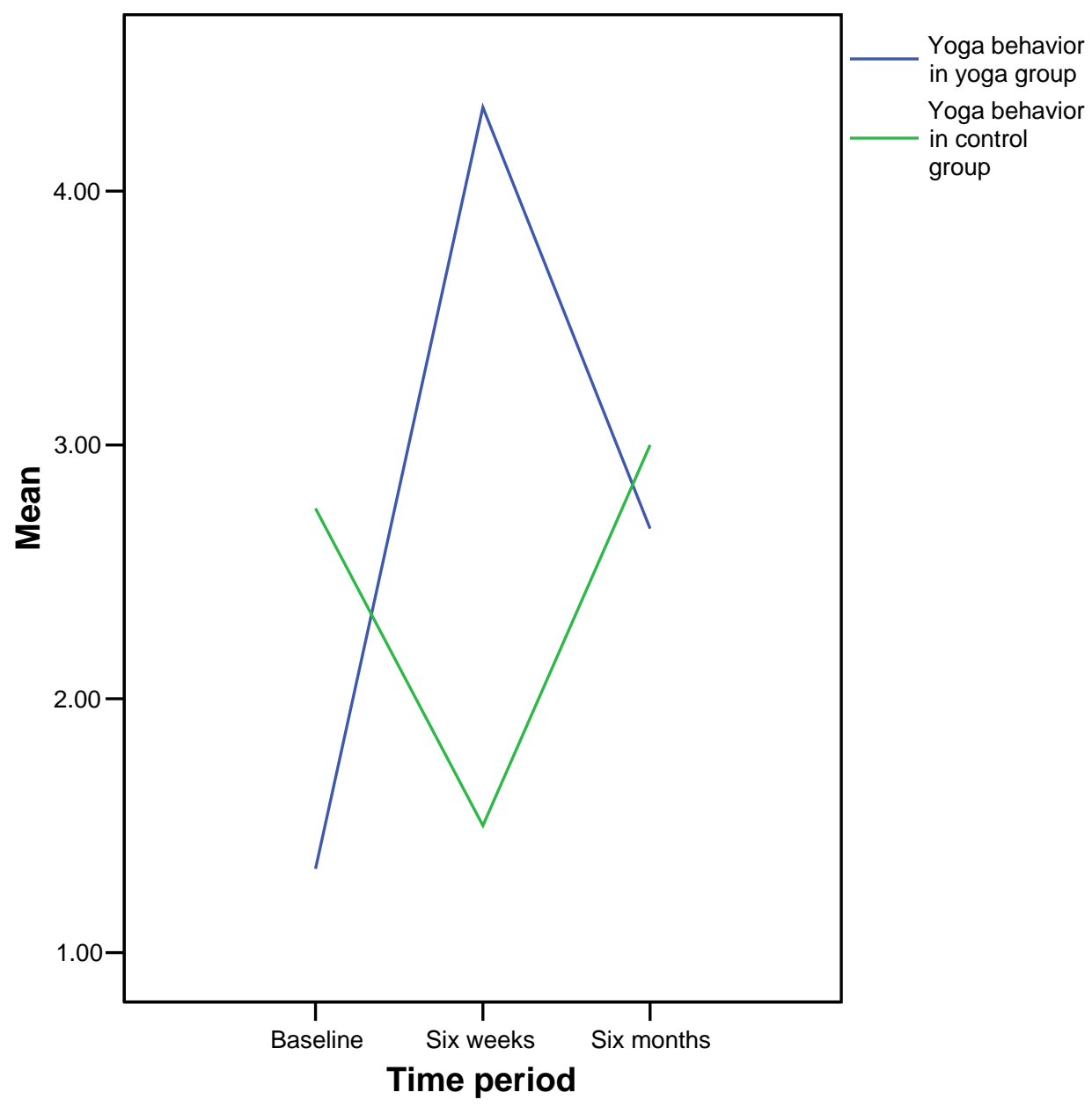

